Article

\title{
The Biodiversity of Saccharomyces cerevisiae in Spontaneous Wine Fermentation: The Occurrence and Persistence of Winery-Strains
}

\author{
Lisa Granchi ${ }^{1, *}$, Donatella Ganucci ${ }^{2}$, Giacomo Buscioni ${ }^{2}$, Silvia Mangani ${ }^{2}$ and \\ Simona Guerrini ${ }^{2}$ (D) \\ 1 Department of Agriculture, Food, Environment and Forestry (DAGRI), University of Florence, \\ Piazzale delle Cascine n. 18, 50144 Florence, Italy \\ 2 FoodMicroTeam s.r.l, Academic Spin-Off of University of Florence, Via Santo Spirito 14, 50125 Florence, Italy; \\ donatella@foodmicroteam.it (D.G.); giacomo@foodmicroteam.it (G.B.); silvia@foodmicroteam.it (S.M.); \\ simona@foodmicroteam.it (S.G.) \\ * Correspondence: lisa.granchi@unifi.it; Tel.: +39-055-275-5916
}

Received: 19 August 2019; Accepted: 24 September 2019; Published: 26 September 2019

\begin{abstract}
Saccharomyces cerevisiae populations occurring in spontaneous wine fermentations display a high polymorphism, although few strains are generally able to dominate the fermentative process. Recent studies have suggested that these indigenous $S$. cerevisiae strains are representative of a specific oenological ecosystem, being associated to a given wine-producing area or a single winery. In contrast, according to other ecological studies, no correlation between genotypic and phenotypic groups of the native S. cerevisiae strains and their origin was found. In this work, several S. cerevisiae strains were isolated in consecutive years from spontaneous fermentations carried out in the same wineries located in different oenological areas in Tuscany, and their persistence was assessed by molecular methods. Some predominant $S$. cerevisiae strains persisted in different fermentations in the same winery from one year to another and they seemed to be representative of a single winery rather than of an oenological area. Therefore, data suggested the idea of the "winery effect" or a microbial terroir at a smaller scale. The use of these typical strains as starter yeasts could provide wines with the distinctive characteristics of a particular winery or sub-zone.
\end{abstract}

Keywords: biodiversity; Saccharomyces cerevisiae; spontaneous wine fermentation; winery-effect

\section{Introduction}

In spontaneous wine fermentation, Saccharomyces cerevisiae yeast, due to its higher alcohol tolerance and other factors responsible for its competitive advantage [1,2], is usually the species predominating the process, although this occurs at different times, depending mainly on the non-Saccharomyces/S. cerevisiae ratio and the properties of yeast species constituting the non-Saccharomyces population [2]. Several studies, by means of various molecular methods, have largely demonstrated that native $S$. cerevisiae populations display a significant genetic diversity and that different strains are simultaneously or in succession involved during the alcoholic fermentation [3-7]. Despite this high polymorphism, generally, a few indigenous S. cerevisiae strains occurring at higher percentages (more than $30-50 \%$ of the total yeast isolates) are able to predominate the fermentative process, while a variable number of strains are present at lower percentages [1,7-12]. The presence of these predominant S. cerevisiae strains has been related to their higher adaptation capability (fitness advantage) to some stress factors of oenological interest, such as increasing ethanol concentrations and temperature changes, along with cell-to-cell contact mechanisms occurring during the alcoholic fermentation [8-10]. 
Furthermore, ecological studies carried out on spontaneous wine fermentations in different wine-making areas all over the world (Spain, Austria, Greece, France, Italy, etc.) highlighted that certain S. cerevisiae strains may persist in the same winery in consecutive years, be shared among the wineries of different wine-making areas; or else be representative of a specific geographical area [2,11-19]. Probably, these strains are better adapted to specific winemaking conditions used in each winery or to the environmental conditions of each oenological area, including climate and agricultural practices, and they could play a key role in determining a distinctive wine's organoleptic properties. Indeed, a significant correlation between the origin of isolation of indigenous S. cerevisiae strains and their effect on the aroma profiles of resulting wines has been shown $[20,21]$. According to these findings, the existence of a "winery effect" and a microbial aspect of terroir has been suggested [5,7,11,20,21], and the selection programs to obtain indigenous $S$. cerevisiae strains to be used as yeast starter cultures to provide wines with distinctive characteristics of a particular winery or enological area, have been promoted.

Nevertheless, it must be stressed that most results were obtained from non-long-term observations, and very few surveys were carried out during consecutive years in the same wine- ecosystem. Furthermore, a recent study on biodiversity of $S$. cerevisiae occurring in spontaneous fermentations in 11 Spanish wineries (Rioja region) during 3-4 consecutive years indicated that there are no representative strains from the winery or the area [22].

Therefore, the aim of this work was to study the genetic diversity of $S$. cerevisiae populations in spontaneous alcoholic fermentations carried out during consecutive vintages in four wineries in Tuscany region (Italy), in order to assess the occurrence and the persistence of yeast strains, which were typical of the winery or zone they came from. The wineries were located in three winemaking areas with controlled designations of origin status (Brunello di Montalcino DOCG, Orcia DOC and Chianti Classico DOCG) and they were selected given that commercial yeast strains had never been used as starter cultures for alcoholic fermentation management.

\section{Materials and Methods}

\subsection{The Isolation of Saccharomyces cerevisiae from Spontaneous Wine Fermentations}

Four wineries located in Tuscany region (Central Italy) in three winemaking areas with controlled designations of origin status were taken into consideration. The main information on oenological conditions (grape variety, number, capacity and material of tanks, temperature control and initial sulphur dioxide concentrations), along with the consecutive years of observations, are reported in Table 1 . In each vintage, grapes were harvested from the same vineyards, and the same tanks were filled up and monitored.

Table 1. The locations and main characteristics of the Tuscany wineries under study, along with observation time.

\begin{tabular}{|c|c|c|c|c|c|c|c|c|}
\hline \multicolumn{9}{|c|}{ Tanks } \\
\hline Winemaking Area & Winery Code & Grape Variety & N. & hL & Materials & $\mathrm{SO}_{2}(\mathrm{mg} / \mathrm{L})$ & $\begin{array}{c}\text { Temperature } \\
\text { Control }\end{array}$ & $\begin{array}{l}\text { Monitoring Time } \\
\text { (Vintages) }\end{array}$ \\
\hline $\begin{array}{l}\text { Val d'Orcia } \\
\text { (Orcia DOC) }\end{array}$ & OC & $\begin{array}{c}\text { Sangiovese } \\
\text { Canaiolo } \\
\text { Pinot noir }\end{array}$ & 6 & 50 & Wood & 30 & Present & 10 \\
\hline \multirow[t]{2}{*}{$\begin{array}{l}\text { Chianti Classico } \\
\text { (DOCG) }\end{array}$} & $\mathrm{CC} 1$ & $\begin{array}{l}\text { Sangiovese } \\
\text { Canaiolo }\end{array}$ & 8 & 120 & $\begin{array}{l}\text { Wood, } \\
\text { steel, } \\
\text { concrete }\end{array}$ & 28 & Absent & 4 \\
\hline & $\mathrm{CC} 2$ & Sangiovese & 8 & 200 & Wood & 30 & Present & 3 \\
\hline
\end{tabular}

The winery coded OC, situated in the Orcia DOC appellation area, is $33 \mathrm{~km}$ far from the BM winery, whereas the two wineries, CC1 and CC2, located in Chianti Classico DOCG appellation area, are $20 \mathrm{~km}$ apart from each other and about $80 \mathrm{~km}$ far from the first cellar (Figure 1). 


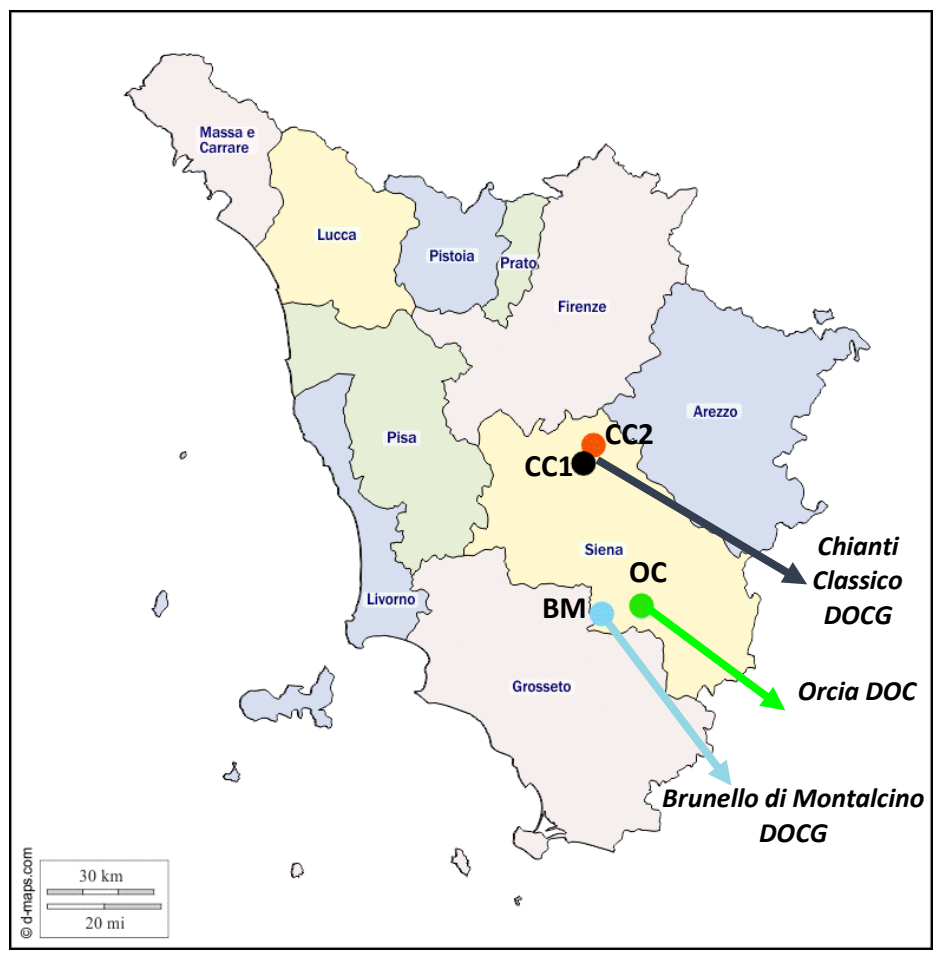

Figure 1. Location of the four wineries (BM, OC, CC1 and CC2) in the Tuscany region.

In all wineries, spontaneous alcoholic fermentations were carried out, and the fermenting must from different grape varieties and different tanks were daily sampled. Saccharomyces cerevisiae populations were quantified by plating serial decimal dilutions of the must/wine samples on WL Nutrient Agar medium (Oxoid Ltd., Basingstoke, Hampshire, UK) containing sodium propionate $(2 \mathrm{~g} / \mathrm{L})$ and streptomycin $(30 \mathrm{mg} / \mathrm{L})$ to inhibit mold and bacterial growth, respectively. Plates were incubated for $48 \mathrm{~h}$ at $30^{\circ} \mathrm{C}$, under aerobic conditions, and then, those containing between 10 and 300 colonies were examined in order to detect colonies belonging to Saccharomyces genus based on colony color and morphology on WL agar. When cell density of $S$. cerevisiae populations reached the maximum value, and during the following quasi-stationary growth phase, a representative number of colonies from the plates of less-diluted must samples were picked up. Isolates from these colonies, were identified by PCR-RFLP analysis of the rDNA internal transcribed spacer (ITS) according to Esteve-Zarzoso et al. [23]. Different number of isolates were analyzed in each vintage according to the size of the vineyards (ha) and the number of filled tanks. S. cerevisiae isolates from each vintage were stored in liquid cultures containing $50 \%(v / v)$ glycerol at $-80{ }^{\circ} \mathrm{C}$ until use.

\subsection{Genotypic Characterization of S. cerevisiae Isolates}

Genotypic characterization of S. cerevisiae isolates was performed by mitochondrial DNA restriction analysis (mtDNA-RFLP) [24]. DNA extraction of each isolate was carried out according to the protocol reported by Querol et al. 1992 [25]. Two microliters of DNA was digested with the restriction endonucleases RsaI and Hinf I according to the instructions of supplier (ThermoFischer Scientific, Milan, Italy). The restriction DNA fragments were separated on $0.8 \%(w / v)$ agarose gels containing ethidium bromide $(1 \mu \mathrm{g} / \mathrm{mL}$ ) by electrophoresis in 1 X-TBE buffer ( $90 \mathrm{mMTris}$-borate, $2 \mathrm{mM}$, EDTA pH 8.0) at $4 \mathrm{Vcm}^{-1}$ for $6 \mathrm{~h}$. The mtDNA-RFLP patterns were captured as TIFF format files with a CCD camera (UVItec Gel Documentation System, Cambridge, UK). Different mt-DNA patterns corresponded to different $S$. cerevisiae strains. 


\subsection{Data Analyses}

For every vintage, in each winery, the total of $S$. cerevisiae isolates from spontaneous wine fermentations carried out in different tanks was calculated. Then, in order to calculate the relative abundance of diverse mt-DNA profiles, i.e., of the different $S$. cerevisiae strains within each winery, the ratio between isolates showing the same mt-DNA profile and total isolates of each winery was evaluated.

S. cerevisiae diversity in each winery was quantified by using the two indices " $\mathrm{H}$ " and "e," as proposed by Shannon-Weaver [26]. The Shannon index $(\mathrm{H})$ measures the diversity within a population taking into account both the number of diverse strains and the number of isolates or clones showing the same genetic profile. The evenness (e) indicates the relative abundance of the diverse strains. Evenness values range from 0 to 1 , with 1 displaying that all strains occurring at the same percentage, i.e., those which are equally abundant in a sample, and values close to 0 meaning the presence of strains at higher percentages or dominant strains. Data were analyzed by one-way ANOVA and Tukey's test $(p<0.05)$ using GraphPad Prism 6 Software.

In addition, all the mt-DNA profiles corresponding to the different $S$. cerevisiae strains recurring in consecutive vintages, in each cellar, were subjected to UPGMA clustering analysis by using Dice coefficient and GelCompar 4.0 software (Applied Math, Kortrijk, Belgium).

\section{Results and Discussion}

\subsection{The Biodiversity of S. cerevisiae Isolates from Different Wineries in Consecutive Vintages}

The biodiversity of $S$. cerevisiae populations was assessed in spontaneous wine fermentations carried out in consecutive vintages (from 3 to 11 years) of four wineries, located in three winemaking areas within DOCG or DOC appellations in Tuscany (Italy), with the aim of evaluating the occurrence and the persistence of some yeast strains, which were typical of the winery or the zone they came from.

A total of 2436 isolates belonging to $S$. cerevisiae species were characterized at the strain level by mitochondrial DNA restriction analysis, and 248 diverse profiles differently distributed according to the winery and the vintage, were obtained (Table 2). In order to quantify the level of genetic diversity of yeast populations occurring in the four wineries over a period of consecutive years, three indices were calculated: the richness indicating the number of diverse mt-DNA profiles; that is, the different S. cerevisiae strains respect to total isolates; the Shannon index $(\mathrm{H})$; and the evenness (e). The $\mathrm{H}$ index increases as both the richness and the evenness of the S. cerevisiae population increase.

The results shown in Table 2 revealed that, independently of the winery, indigenous S. cerevisiae populations showed a high amount of polymorphism, confirming the general trend reported in the literature on spontaneous wine fermentations [2-8,11-19,22,24]. However, considering the frequency of different $S$. cerevisiae strains within each winery in the various vintages, showed one or two predominant strains occurring at high frequencies $(>25 \%)$, in association with a variable number of secondary strains at low frequencies $(<10 \%)$, (Table 2$)$. In addition, some predominant strains were shared by different grape varieties fermented in various tanks, pointing out that no correlation occurred between specific yeast strains and the grape variety, as reported by Ganucci et al. [8]. The occurrence of a few predominant $S$. cerevisiae strains at percentages $>25 \%$ carrying out the spontaneous wine fermentations, is consistent with many other studies accomplished in different oenological regions [6-8,11-13,19]. Recently, some researchers suggested that different factors are involved in determining the dominance of one S. cerevisiae strain over another in spontaneous wine fermentations, such as ethanol and temperature adaptation, differential sulphur dioxide production and resistance, killer activity and the cell-to-cell contact in mixed cultures in the same environment [8].

In this study, only in vintage 9 of the winery BM, were predominant strains not found, as all strains showed frequencies lower than $10 \%$. Indeed, the evenness index was 0.99 , which was the highest value, indicating that the 18 strains showed very similar relative abundances within the S. cerevisiae population, and the $\mathrm{H}$ index reached the maximum value, representing a high level of 
diversity. This vintage was characterized by high rainfall during the final days before grape harvest (data not shown) and the genetic diversity level was probably affected by such an environmental factor. Indeed, some studies reported that rainy vintages were associated with higher [27] or lower yeast biodiversity [28] of S. cerevisiae populations.

Table 2. The biodiversity of $S$. cerevisiae strains occurring in Tuscany wineries located in three different wine areas $(\mathrm{BM}=$ Brunello di Montalcino DOGC, $\mathrm{OD}=$ Orcia DOC and CC $=$ Chianti Classico DOCG) during consecutive vintages. (Richness = number of different mt-DNA profiles; i.e., different S. cerevisiae strains; $\mathrm{H}$ and $\mathrm{e}=$ evenness indicates the Shannon-Weaver index [26]).

\begin{tabular}{|c|c|c|c|c|c|c|c|c|}
\hline Winery & Vintage & $\begin{array}{c}\text { N. of S. cerevisiae } \\
\text { Isolates }\end{array}$ & Richness & $\mathbf{H}$ & e & $\begin{array}{c}\text { Strains at } \\
\text { Frequency }>25 \%\end{array}$ & $\begin{array}{c}\text { Strains at } \\
\text { Frequency } 10-25 \%\end{array}$ & $\begin{array}{c}\text { Strains at } \\
\text { Frequency }<10 \%\end{array}$ \\
\hline \multirow[t]{11}{*}{$\mathrm{BM}$} & 1 & 23 & 10 & 1.94 & 0.84 & 1 & 1 & 8 \\
\hline & 2 & 26 & 11 & 2.10 & 0.87 & 1 & 3 & 7 \\
\hline & 3 & 20 & 9 & 2.17 & 0.98 & 1 & 5 & 3 \\
\hline & 4 & 21 & 13 & 2.19 & 0.85 & 1 & - & 12 \\
\hline & 5 & 30 & 10 & 1.87 & 0.81 & 1 & 1 & 8 \\
\hline & 6 & 20 & 8 & 1.78 & 0.85 & 2 & 2 & 4 \\
\hline & 7 & 24 & 9 & 1.66 & 0.75 & 1 & 2 & 6 \\
\hline & 8 & 36 & 15 & 2.11 & 0.78 & 1 & 1 & 13 \\
\hline & 9 & 31 & 18 & 2.88 & 0.99 & - & - & 18 \\
\hline & 10 & 37 & 9 & 1.53 & 0.70 & 2 & - & 7 \\
\hline & 11 & 38 & 12 & 2.09 & 0.84 & 1 & 3 & 8 \\
\hline \multirow[t]{10}{*}{ OD } & 1 & 117 & 10 & 1.88 & 0.82 & 1 & 2 & 7 \\
\hline & 2 & 120 & 2 & 0.44 & 0.63 & 1 & 1 & - \\
\hline & 3 & 140 & 7 & 1.03 & 0.53 & 2 & - & 5 \\
\hline & 4 & 120 & 9 & 1.33 & 0.60 & 1 & 1 & 7 \\
\hline & 5 & 120 & 4 & 0.41 & 0.30 & 1 & - & 3 \\
\hline & 6 & 100 & 5 & 0.69 & 0.43 & 1 & 1 & 3 \\
\hline & 7 & 140 & 9 & 1.87 & 0.85 & 1 & 3 & 5 \\
\hline & 8 & 120 & 10 & 2.00 & 0.87 & 1 & 3 & 6 \\
\hline & 9 & 140 & 9 & 1.29 & 0.59 & 1 & 2 & 6 \\
\hline & 10 & 140 & 6 & 0.67 & 0.42 & 1 & 1 & 4 \\
\hline \multirow[t]{4}{*}{ CC1 } & 1 & 137 & 11 & 1.40 & 0.58 & 1 & 2 & 8 \\
\hline & 2 & 134 & 9 & 1.83 & 0.83 & 1 & 4 & 4 \\
\hline & 3 & 126 & 4 & 0.68 & 0.49 & 1 & 1 & 2 \\
\hline & 4 & 114 & 5 & 0.63 & 0.46 & 1 & 1 & 1 \\
\hline \multirow[t]{3}{*}{$\mathrm{CC} 2$} & 1 & 94 & 7 & 0.98 & 0.51 & 1 & 1 & 5 \\
\hline & 2 & 144 & 6 & 1.67 & 0.93 & 1 & 5 & - \\
\hline & 3 & 124 & 11 & 2.05 & 0.86 & 1 & 3 & 7 \\
\hline
\end{tabular}

In order to compare the genetic diversity levels of the $S$. cerevisiae populations isolated from the four wineries during the observation time, the average values of " $\mathrm{H}$ " and " $\mathrm{e}$ " indices were calculated (Table 3) and one-way ANOVA was performed. Significant differences among the wineries were found, with the cellars BM and CC2 showing a higher diversity level than the others. Many environmental factors, such as the vineyards management with organic or conventional practices are reported to affect the levels of $S$. cerevisiae strain diversity $[17,29]$. In the winery BM, which had the highest diversity of $S$. cerevisiae strains $(\mathrm{H}=2.03)$, organic viticulture practices have always been used from the vineyard's implantation. By contrast, in the cellar CC2, which showed a diversity level comparable to the BM winery, the vineyards were managed with conventional practices. Hence, our results did not support that different viticulture practices affect $S$. cerevisiae strain diversity, in agreement with other studies [29].

One plausible explanation for these observations is that the level of genetic diversity of S. cerevisiae populations in spontaneous wine fermentations depends not only on climatic factors or viticulture practices, but also on to multi-factorial influences, including the fermentation management, which together, constitute the specific ecological niche for each yeast population. Therefore, the genetic polymorphisms found in these yeast populations analyzed by RFLP-mtDNA could be a result of a constant adaptation to the ecological conditions they are exposed to $[19,29]$. The understanding of the adaptation phenomena to the wine related environment might have, therefore, a key role in explaining genetic diversity of wine yeast [30].

Anyway, the values found for S. cerevisiae populations fall within the range of the Shannon-Weaver diversity index, which usually varies from 1.5 to 3.5 [31]. 
Table 3. Diversity indices calculated according to Shannon-Weaver [26] for the S. cerevisiae population obtained from the four wineries located in different winemaking areas (BM = Brunello di Montalcino DOGC, OD = Orcia DOC, and CC1 and CC2 = Chianti Classico DOCG). Values are expressed as means \pm SEs; different superscript letters $\left({ }^{a}\right.$ and $\left.{ }^{b}\right)$ within the same column indicate significant differences (ANOVA, Tukey's test at $p<0.05$ ).

\begin{tabular}{ccc}
\hline Winery & $\mathbf{H}$ & Evenness \\
\hline $\mathrm{BM}$ & $2.03 \pm 0.22^{\mathrm{a}}$ & $0.84 \pm 0.07^{\mathrm{a}}$ \\
$\mathrm{OC}$ & $1.11 \pm 0.30^{\mathrm{b}}$ & $0.60 \pm 0.09^{\mathrm{b}}$ \\
$\mathrm{CC} 1$ & $1.36 \pm 0.30^{\mathrm{b}}$ & $0.59 \pm 0.12^{\mathrm{ab}}$ \\
$\mathrm{CC} 2$ & $1.57 \pm 0.33^{\mathrm{ab}}$ & $0.77 \pm 0.10^{\mathrm{ab}}$ \\
\hline
\end{tabular}

\subsection{The Persistence of S. cerevisiae Strains in Different Wineries in Consecutive Vintages}

To assess whether S. cerevisiae strains occurred in consecutive vintages in the same winery or in wineries located in different winemaking areas in Tuscany, the mt-DNA profiles detected for each vintage in the four wineries were compared, and the relative frequencies of isolation expressed as percentages, were calculated. In Tables 4 and 5, the percentages of S. cerevisiae strains recurring in various vintages in the four wineries are reported.

In the winery BM, 21 strains out of 124, which were identified by different mt-DNA profiles, appeared in more than one vintage (Table 4). Among these recurrent S. cerevisiae strains, four (BM-I, $\mathrm{BM}-\mathrm{V}, \mathrm{BM}-\mathrm{VI}$ and $\mathrm{BM}-\mathrm{XV}$ ) were the dominant strains at least in one vintage, displaying percentages greater or equal to $25 \%$. Particularly, the S. cerevisiae strain corresponding to BM-VI mt-DNA profile was present in 10 of the 11 consecutive vintages under study, and it was predominant in five vintages, attaining frequencies ranging from $30 \%$ to $45 \%$. On the contrary, the other recurring S. cerevisiae strains, BM-I, BM-V and BM-XV, were dominant only in a vintage with percentages of $27 \%, 25 \%$ and $38 \%$, respectively.

In the winery OC, where a total of 71 S. cerevisiae strains during the 10 vintages studied were found, 14 strains recurred in different years (from two to nine). Four strains exhibited percentages higher than $27 \%$, and thus, they were dominant. The strains OC-IV and OC-XI were dominant with similar frequencies (about 30\%) in the vintage 3 and 8, respectively. The strain OC-VIII was dominant in four consecutive vintages and it appeared at high percentages, ranging from $60 \%$ to $90 \%$, whereas the strain OC-XIV was dominant in two years at frequencies of $55 \%$ and $83 \%$ (Table 4 ). Indeed, the S. cerevisiae populations in vintages in which some strains appeared at percentages higher than $82 \%$, showed the lowest values of evenness index (Table 3).

In the winery $\mathrm{CC} 1$, seven $S$. cerevisiae strains out of 29 , were recurring in the four vintages considered, and three were dominant: the strains $\mathrm{CC}_{1}$-II and $\mathrm{CC}_{1}$-VI both showed a frequency of $80 \%$, in the vintage 3 and 4 , respectively, while the strain $\mathrm{CC}_{1}$-III occurred in two consecutive years at percentages of $32 \%$ and $51 \%$ (Table 5 ).

In the winery CC2, spontaneous wine fermentations were monitored only for three consecutive vintages. Among a total of $15 \mathrm{~S}$. cerevisiae strains, four strains were present in two or three vintages. Notably, the strains $\mathrm{CC}_{2}$-I and $\mathrm{CC}_{2}$-II were clearly dominant at frequencies of $71 \%$ and $32 \%$ in the first and third years of observation, respectively (Table 5).

In summary, independently of the winery and the length of observation time, recurrent and predominant $S$. cerevisiae strains carrying out spontaneous wine fermentations were found in agreement with other authors that highlighted the persistence of some strains over consecutive years in the same cellar $[11,13,14,32]$.

Moreover, the comparison among the mt-DNA profiles corresponding to the $46 \mathrm{~S}$. cerevisiae strains recurrent in the four wineries in different vintages revealed that there was no common profile. Cluster analysis of similarity among the mt-DNA patterns obtained with RsaI, was also performed. The resulting dendrogram indicated that the S. cerevisiae strains, at $50 \%$ of similarity, grouped into five clusters, mainly based on the winery where they came from (Figure 2). In particular, the clusters 2 
and 3 were comprised of only S. cerevisiae strains isolated from the BM winery, and cluster 5 included S. cerevisiae strains all isolated from the winery OC. On the contrary, in clusters 1 and 4 , strains isolated from two cellars were grouped, although the majority of strains came from a single cellar.

Table 4. Frequency (\%) of S. cerevisiae strains recurring in two wineries (BM = Brunello di Montalcino DOCG and OC $=$ Orcia DOC) in different vintages (underlined the predominant strains).

\begin{tabular}{|c|c|c|c|c|c|c|c|c|c|c|c|}
\hline \multirow[t]{2}{*}{ Strain } & \multicolumn{11}{|c|}{ Vintage } \\
\hline & 1 & 2 & 3 & 4 & 5 & 6 & 7 & 8 & 9 & 10 & 11 \\
\hline BM-I & 8.8 & 26.9 & - & - & - & - & $\underline{50}$ & - & - & - & - \\
\hline$\overline{\mathrm{BM}-\mathrm{II}}$ & 4.3 & - & 10 & - & - & - & - & - & - & - & - \\
\hline BM-III & 4.3 & - & - & - & 9.9 & - & - & - & - & - & - \\
\hline BM-IV & 8.8 & - & - & 9.4 & - & - & - & - & - & - & - \\
\hline BM-V & - & 3.8 & $\underline{25}$ & - & - & - & - & 2.7 & 3.3 & 5.4 & 1.5 \\
\hline$\overline{\mathrm{BM}-\mathrm{VI}}$ & - & 3.8 & $\overline{5}$ & $\underline{38.3}$ & 6.6 & $\underline{30}$ & 4.1 & $\underline{44.4}$ & 6.6 & 37.8 & $\underline{45}$ \\
\hline$\overline{\text { BM-VII }}$ & - & 19.2 & 10 & $\overline{-}$ & - & $\overline{-}$ & - & $\overline{-}$ & - & $\overline{-}$ & $\overline{-}$ \\
\hline BM-VIII & - & 3.8 & - & 4.7 & - & - & - & - & - & - & - \\
\hline BM-IX & - & 11.5 & 15 & - & 3.3 & - & - & - & - & - & - \\
\hline BM-X & - & - & 15 & - & - & 10 & - & - & - & 2.7 & - \\
\hline BM-XI & - & - & - & - & - & 10 & - & 2.7 & - & - & - \\
\hline BM-XII & - & - & - & - & - & - & - & - & 6.6 & 2.7 & - \\
\hline BM-XIII & - & - & - & - & - & 5 & 4.1 & 13.5 & - & - & - \\
\hline BM-XIV & - & - & - & - & - & - & 12.3 & 2.7 & - & - & - \\
\hline BM-XV & - & - & - & - & - & - & - & 5.4 & 9.7 & 37.8 & 3 \\
\hline$\overline{\mathrm{BM}-X V I}$ & - & - & - & - & - & - & - & 5.4 & - & $\overline{-}$ & 8 \\
\hline BM-XVII & - & - & - & - & - & - & - & 2.7 & 13.2 & - & 8 \\
\hline BM-XVIII & I - & - & - & - & - & - & 4.1 & 2.7 & - & - & - \\
\hline BM-XIX & - & - & - & - & - & - & - & 2.7 & - & - & 1.5 \\
\hline BM-XX & - & - & - & - & - & - & - & - & 3.3 & 2.7 & 8 \\
\hline BM-XXI & - & - & - & - & - & - & - & - & - & 2.7 & 3 \\
\hline OC-I & 0.7 & - & 1.6 & 15.7 & - & - & - & - & 22.9 & 1.9 & \\
\hline OC-II & - & - & - & - & 0.8 & 2.9 & - & - & - & - & \\
\hline OC-III & 16.9 & - & 1.6 & 7.8 & 3.1 & 10.3 & 3 & 9 & & & \\
\hline OC-IV & 6.3 & 16 & 27.8 & 5.5 & 5.6 & - & 5.9 & 2.8 & 12.9 & 10 & \\
\hline$\overline{\mathrm{OC}-\mathrm{V}}$ & 7 & - & $\overline{-}$ & 1.2 & - & - & - & - & - & - & \\
\hline OC-VI & 7.8 & - & 3.4 & 1.8 & - & - & - & - & - & - & \\
\hline OC-VII & 3.1 & - & 2.5 & 6.8 & - & - & - & - & - & - & \\
\hline OC-VIII & 14.8 & 4 & 62.3 & $\underline{60}$ & $\underline{90.5}$ & 81.7 & - & - & 0.7 & - & \\
\hline$\overline{\text { OC-IX }}$ & 1.3 & - & $\overline{-}$ & $\overline{-}$ & $\overline{-}$ & $\overline{-}$ & 22.1 & 23 & 2.9 & 1.7 & \\
\hline OC-X & - & - & - & 0.6 & - & - & 7.1 & - & - & - & \\
\hline OC-XI & - & - & - & - & - & - & - & 2.4 & $\underline{31}$ & 20.2 & \\
\hline$\overline{\text { OC-XII }}$ & - & - & - & - & - & - & 12.1 & 6.3 & $\overline{3.6}$ & 2.1 & \\
\hline OC-XIII & - & - & - & - & - & - & 13 & - & 0.7 & 1.4 & \\
\hline OC-XIV & - & - & - & - & - & - & - & 17.4 & $\underline{55}$ & 82.9 & \\
\hline
\end{tabular}


Table 5. The frequency (\%) of $S$. cerevisiae strains recurring in two wineries $\left(\mathrm{CC}_{1}\right.$ and $\mathrm{CC}_{2}$ located in the Chianti Classico wine area) in different vintages (underlined the predominant strains).

\begin{tabular}{|c|c|c|c|c|}
\hline \multirow[t]{2}{*}{ Strain } & \multicolumn{4}{|c|}{ Vintage } \\
\hline & 1 & 2 & 3 & 4 \\
\hline $\mathrm{CC}_{1-\mathrm{I}}$ & 15 & 12.5 & 4.5 & - \\
\hline $\mathrm{CC}_{1}-\mathrm{II}$ & 3 & - & $\underline{81}$ & 13 \\
\hline$\overline{\mathrm{CC}_{1}-\mathrm{III}}$ & 51.5 & 31.6 & $\overline{10}$ & - \\
\hline$\overline{\mathrm{CC}_{1}-\mathrm{IV}}$ & $\overline{8.8}$ & $\overline{1.4}$ & - & - \\
\hline $\mathrm{CC}_{1}-\mathrm{V}$ & 0.8 & 2.8 & - & - \\
\hline $\mathrm{CC}_{1}$-VI & 1.4 & 13.8 & - & $\underline{80}$ \\
\hline$\overline{\mathrm{CC}_{1}-\mathrm{VII}}$ & - & 16.8 & 4.5 & $\overline{7}$ \\
\hline $\mathrm{CC}_{2}-\mathrm{I}$ & $\underline{71}$ & 12.5 & 14.5 & \\
\hline$\overline{\mathrm{CC}_{2}-\mathrm{II}}$ & $\overline{1}$ & 12.5 & 32 & \\
\hline$\overline{\mathrm{CC}_{2}-\mathrm{III}}$ & 1 & - & 2.5 & \\
\hline $\mathrm{CC}_{2}-\mathrm{IV}$ & - & 12.5 & 12 & \\
\hline
\end{tabular}

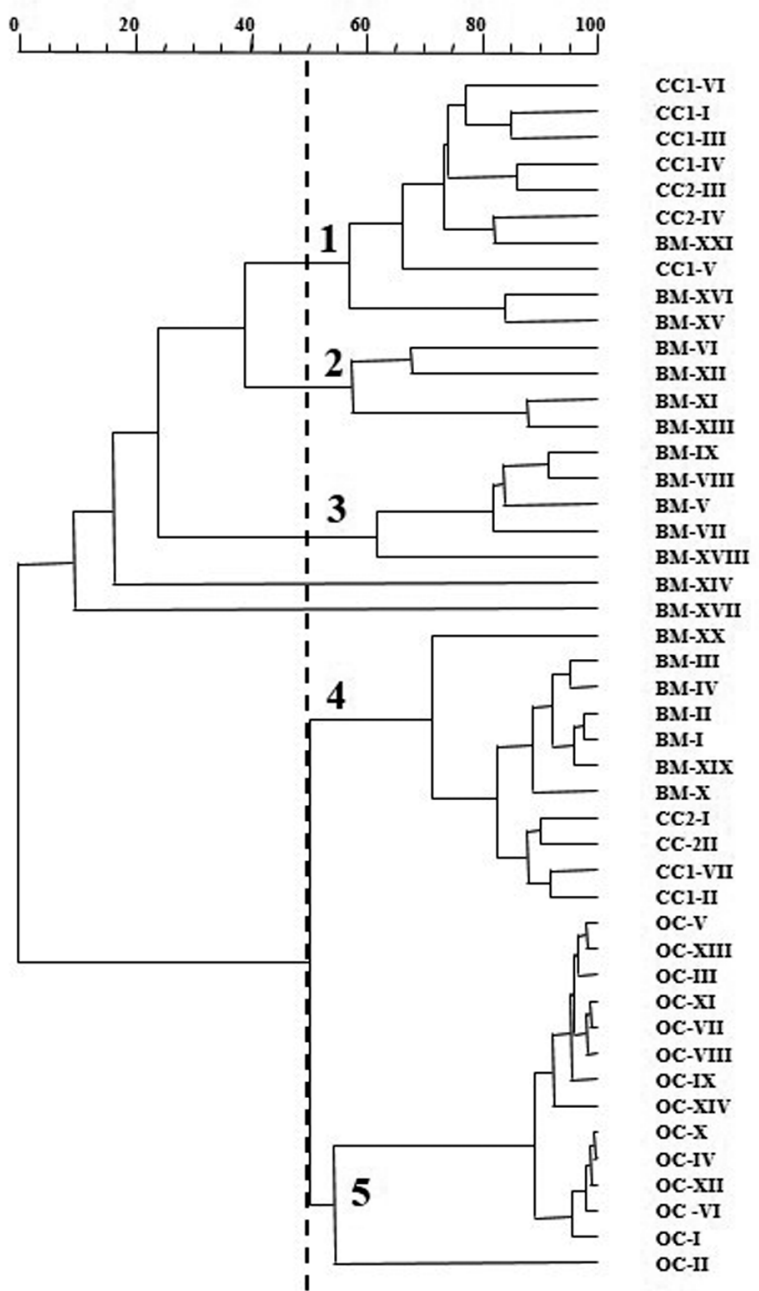

Figure 2. Dendrogram from UPGMA clustering analysis, based on the Dice coefficient of mt-DNA RsaI restriction patterns of the $S$. cerevisiae strains recurring in spontaneous wine fermentations carried out in four different wineries (BM, OC, CC1 and cc2) in Tuscany (Italy). Arabic numerals at 50\% similarity indicate the different clusters. 
Therefore, according to our results, these $S$. cerevisiae strains seem to be representative of single winery rather than of an oenological area. In fact, despite the two CC1 and CC2 cellars belonging to the same area (Chianti Classico DOCG) and being about $20 \mathrm{~km}$ apart, they exhibited different indigenous strains. Analogous results were obtained for the wineries BM and OC, which are $30 \mathrm{~km}$ apart.

In contrast, other works showed the existence of common strains between different wineries of the same wine-producing area, suggesting that they were representative of a specific enological ecosystem [3,7,11,19,22,33], and Knight et al. [21] found a correlation between specific genotypes and a particular region, supporting the concept that specific native $S$. cerevisiae strains could be associated with a terroir. However, the forces shaping S. cerevisiae's population structures are still poorly understood; some studies demonstrated that regional, site-specific grape variety factors andvineyard specific climatic features determine the existence of a nonrandom "microbial terroir" as a decisive factor in the variation among regional wine fermentations [34,35]. Probably, genetic differences are responsible of the ability of $S$. cerevisiae populations to adapt to varied environmental and stress conditions [33].

Our findings suggest the idea of the "winery effect," as reported by Vezinhet et al. [11] or of a microbial terroir at a smaller scale. In each winery, a probable, high locally-selective pressure resulting from specific wine production style might be the origin of particular genetic yeast patterns. Hence, the selected S. cerevisiae strains, being better adapted to conditions used, can predominate and persist over other yeast strains contributing to the typical sensory properties of local wines.

\section{Conclusions}

The aim of this study was to investigate in consecutive vintages (from 3 to 11), the genotypic diversity of indigenous $S$. cerevisiae populations occurring in spontaneous wine fermentations was measured, taking from four wineries (located in three oenological areas in Tuscany, Italy), in order to assess the possible existence of typical winery-strains.

A total of 238 S. cerevisiae strains were obtained from 2436 isolates by RFLP-mt-DNA analysis. Despite the high quantity of polymorphisms, a few dominant strains at frequencies higher than $25 \%$ were found in each winery during the vintages considered. The genomic diversity levels of indigenous S. cerevisiae populations varied with the vintage, probably due to different environmental factors, including climate conditions and vineyard management practices.

Independently to the winery and the number of vintages considered, some strains of S. cerevisiae recurred in consecutive years in the same winery, although at different percentages. However, for each winery, one or two predominant strains occurred in several vintages (no strain being common among different wineries), belonging to three winemaking areas with controlled designations of origin status. The S. cerevisiae strains recurring in each winery at higher frequencies could be better adapted to their own environment.

Therefore, the results obtained in this study highlight the persistence of winery typical strains, suggesting the idea of the "winery effect" or a microbial terroir at a smaller scale, in respect to other surveys. The occurrence of specific S. cerevisiae strains in each winery supports the potential role of these microorganisms in determining distinctive wines' characteristics, and their selection could represent a resource to contribute to preserving the typicality of wines [11,20] Indeed, recurrent $S$. cerevisiae strains in a winery could become a strategic activity for the winemakers, because it may link territory, environment and final products for local wine valorization.

Author Contributions: Conceptualization, L.G. and S.G.; investigation, D.G., S.M. and G.B.; resources, G.B.; data curation, S.G.; writing—original draft preparation, L.G. and S.G.; writing-review and editing, L.G., S.G., D.G. and G.B.; supervision, L.G.

Funding: This research received no external funding.

Conflicts of Interest: The authors declare no conflict of interest. 


\section{References}

1. Pretorius, I.S. Tailoring wine yeast for the new millennium: Novel approaches to the ancient art of winemaking. Yeast 2000, 16, 675-729. [CrossRef]

2. Bisson, L.F. Geographic origin and diversity of wine strains of Saccharomyces. Am. J. Enol. Vitic. 2012, 63, 165-175. [CrossRef]

3. Schuller, D.; Casal, M. The genetic structure of fermentative vineyard-associated Saccharomyces cerevisiae populations revealed by microsatellite analysis. Antonie Van Leeuwenhoek 2007, 91, 137-150. [CrossRef]

4. Combina, M.; Elía, A.; Mercado, L.; Catania, C.; Ganga, A.; Martinez, C. Dynamics of indigenous yeast populations during spontaneous fermentation of wines from Mendoza, Argentina. Int. J. Food Microbiol. 2005, 99, 237-243. [CrossRef]

5. Mercado, L.; Sturm, M.E.; Rojo, M.C.; Ciklic, I.; Martínez, C.; Combina, M. Biodiversity of Saccharomyces cerevisiae populations in Malbec vineyards from the "Zona Alta del Río Mendoza" region in Argentina. Int. J. Food Microbiol. 2011, 151, 319-326. [CrossRef]

6. Capece, A.; Romaniello, R.; Siesto, G.; Romano, P. Diversity of Saccharomyces cerevisiae yeasts associated to spontaneously fermenting grapes from an Italian "heroic vine-growing area". Food Microbiol. 2012, 31, 159-166. [CrossRef]

7. Versavaud, A.; Courcoux, P.; Roulland, C.; Dulau, L.; Hallet, J.N. Genetic diversity and geographical distribution of wild Saccharomyces cerevisiae strains from the wine-producing area of Charentes, France. Appl. Environ. Microbiol. 1995, 61, 3521-3529.

8. Ganucci, D.; Guerrini, S.; Mangani, S.; Vincenzini, M.; Granchi, L. Quantifying the effects of ethanol and temperature on the fitness advantage of predominant Saccharomyces cerevisiae strains occurring in spontaneous wine fermentations. Front. Microbiol. 2018, 9, 1563. [CrossRef]

9. Perrone, B.; Giacosa, S.; Rolle, L.; Cocolin, L.; Rantsiou, K. Investigation of the dominance behavior of Saccharomyces cerevisiae strains during wine fermentation. Int. J. Food Microbiol. 2013, 165, 156-162. [CrossRef]

10. Pérez-Torrado, R.; Rantsiou, K.; Perrone, B.; Navarro-Tapia, E.; Querol, A.; Cocolin, L. Saccharomyces cerevisiae strains: Insight into the dominance phenomenon. Sci. Rep. 2017, 7, 43603. [CrossRef]

11. Vezinhet, F.; Hallet, J.N.; Valade, M.; Poulard, A. Ecological survey of wine strains by molecular methods of identification. Am. J. Enol. Vitic. 1992, 43, 83-86.

12. Gutièrrez, A.R.; Santamarìa, R.; Epifanio, S.; Garijo, P.; Lopez, R. Ecology of spontaneous fermentation in one winery during 5 consecutive years. Lett. Appl. Microbiol. 1999, 29, 411-415. [CrossRef]

13. Sabate, J.; Cano, J.; Querol, A.; Guillamon, J.M. Diversity of Saccharomyces strains in wine fermentations: Analysis for two consecutive years. Lett. Appl. Microbiol. 1998, 26, 452-455. [CrossRef]

14. Torija, M.; Rozès, N.; Poblet, M.; Guillamón, J.M.; Mas, A. Yeast population dynamics in spontaneous fermentations: Comparison between two different wine-producing areas over a period of three years. Antonie Van Leeuwenhoek 2001, 79, 345-352. [CrossRef]

15. Lopandic, K.; Gangl, H.; Wallner, E.; Tscheik, G.; Leitner, G.; Querol, A.; Gardner, R.C.; Sterflinger, K.; Prillinger, H. Genetically different wine yeasts isolated from Austrian vine-growing regions influence wine aroma differently and contain putative hybrids between Saccharomyces cerevisiae and Saccharomyces kudriavzevii. FEMS Yeast Res. 2007, 7, 953-965. [CrossRef]

16. Pramateftaki, P.V.; Lanaridis, P.; Typas, M.A. Molecular identification of wine yeasts at species or strain level: A case study with strains from two vine-growing areas of Greece. J. Appl. Microbiol. 2000, 89, 236-248. [CrossRef]

17. Börlin, M.; Venet, P.; Claisse, O.; Salin, F.; Legras, J.L.; Masneuf-Pomarede, I. Cellar-associated Saccharomyces cerevisiae population structure revealed high level diversity and perennial persistence at Sauternes wine estates. Appl. Environ. Microbiol. 2016, 82, 2909-2918. [CrossRef]

18. Cocolin, L.; Pepe, V.; Comitini, F.; Comi, G.; Ciani, M. Enological and genetic traits of Saccharomyces cerevisiae isolated from former and modern wineries. FEMS Yeast Res. 2004, 3, 237-245. [CrossRef]

19. Capece, A.; Granchi, L.; Guerrini, S.; Mangani, S.; Romaniello, R.; Vincenzini, M.; Romano, P. Diversity of Saccharomyces cerevisiae strains isolated from two italian wine-producing regions. Front. Microbiol. 2016, 7, 1018. [CrossRef] 
20. Bokulich, N.A.; Collins, T.S.; Masarweh, C.; Allene, G.; Heymann, H.; Ebeler, S.E.; Mills, D.A. Associations among wine grape microbiome, metabolome, and fermentation behavior suggest microbial contribution to regional wine characteristics. MBio 2016, 7, e00631. [CrossRef]

21. Knight, S.; Klaere, S.; Fedrizzi, B.; Goddard, M.R. Regional microbial signatures positively correlate with differential wine phenotypes: Evidence for a microbial aspect to terroir. Sci. Rep. 2015, 5, 14233. [CrossRef]

22. Santamaría, P.; López, R.; del Patrocinio Garijo, M.; Escribano, R.; González-Arenzana, L.; López-Alfaro, I.; Gutiérrez, A.R. Biodiversity of Saccharomyces cerevisiae Yeasts in Spontaneous Alcoholic Fermentations: Typical Cellar or Zone Strains? In Grape and Wine Biotechnology; Morata, A., Loira, I., Eds.; IntechOpen: London, UK, 2019; pp. 1-15, ISBN 978-953-51-2693-5. [CrossRef]

23. Esteve-Zarzoso, B.; Belloch, C.; Uruburu, F.; Querol, A. Identification of yeast by RFLP analysis of the 5.8 rRNA and the two ribosomal internal transcribed spacers. Int. J. Syst. Bacteriol. 1999, 49, 329-337. [CrossRef]

24. Granchi, L.; Ganucci, D.; Viti, C.; Giovannetti, L.; Vincenzini, M. Saccharomyces cerevisiae biodiversity in spontaneous commercial fermentations of grape musts with adequate and inadequate assimilable-nitrogen content. Lett. Appl. Microbiol. 2003, 36, 54-58. [CrossRef]

25. Querol, A.; Barrio, E.; Huerta, T.; Ramón, D. Molecular monitoring of wine fermentations conducted by active dry yeast strains. Appl. Environ. Microbiol. 1992, 58, 2948-2953.

26. Shannon, S.E.; Weaver, W. The Mathematical Theory of Communication; University of Illinois Press: Urbana, IL, USA, 1963.

27. Longo, E.; Cansado, J.; Agrelo, D.; Villa, T.G. Effect of climatic conditions on yeast diversity in grape musts from northwest Spain. Am. J. Enol. Vitic. 1991, 42, 141-144.

28. Rementeria, A.; Rodriguez, J.A.; Cadaval, A.; Amenabar, R.; Muguruza, J.R.; Hernando, F.L.; Sevilla, M.J. Yeast associated with spontaneous fermentations of white wines from the "Txakoli de Bizkaia" region (Basque Country, North Spain). Int. J. Food Microbiol. 2003, 86, 201-207. [CrossRef]

29. De Celis, M.; Ruiz, J.; Martín-Santamaría, M.; Alonso, A.; Marquina, D.; Navascués, E.; Gómez-Flechoso, M.A.; Belda, I.; Santos, A. Diversity of Saccharomyces cerevisiae yeasts associated to spontaneous and inoculated fermenting grapes from Spanish vineyards. Lett. Appl. Microbiol. 2019, 68, 580-588. [CrossRef]

30. Tofalo, R.; Perpetuini, G.; Schirone, M.; Fasoli, G.; Aguzzi, I.; Corsetti, A. Biogeographical characterization of Saccharomyces cerevisiae wine yeast by molecular methods. Front. Microbiol. 2013, 4, 166. [CrossRef]

31. Ortiz-Burgos, S. Shannon-Weaver Diversity Index. In Encyclopedia of Estuaries. Encyclopedia of Earth Sciences Series; Kennish, M.J., Ed.; Springer: Dordrecht, The Netherlands, 2016; p. 572.

32. Frezier, V.; Dubourdieu, D. Ecology of yeast strains Saccharomyces cerevisiae during spontaneous fermentation in Bordeaux winery. Am. J. Enol. Vitic. 1992, 43, 375-380.

33. Tofalo, R.; Perpetuini, G.; Fasoli, G.; Schirone, M.; Corsetti, A.; Suzzi, G. Biodiversity study of wine yeasts belonging to the "terroir" of Montepulciano d'Abruzzo "Colline Teramane" revealed Saccharomyces cerevisiae strains exhibiting a typical and "unique 5.8S-ITS restriction patterns". Food Microbiol. 2014, 39, 7-12. [CrossRef]

34. Schuller, D.; Cardoso, F.; Sousa, S.; Gomes, P.; Gomes, A.C.; Santos, M.A.S.; Casal, M. Genetic diversity and population structure of Saccharomyces cerevisiae strains isolated from different grape varieties and winemaking regions. PLoS ONE 2012, 7, e32507. [CrossRef]

35. Bokulich, N.A.; Thorngate, J.H.; Richardson, P.M.; Mills, D.A. Microbial biogeography of wine grapes is conditioned by cultivar, vintage, and climate. Proc. Natl. Acad. Sci. USA 2014, 111, E139-E148. [CrossRef]

(C) 2019 by the authors. Licensee MDPI, Basel, Switzerland. This article is an open access article distributed under the terms and conditions of the Creative Commons Attribution (CC BY) license (http://creativecommons.org/licenses/by/4.0/). 